\title{
MATSU CULTURAL HERITAGE AND ITS CONSERVATION IN BOHAI RIM -CASE STUDY ON THE HALL OF FUJIAN IN YANTAI
}

\author{
Shuran Yao \\ Architecture School, Southeast University, Nanjing, Sipailou 2\#,Nanjing,China - ashuy@126.com
}

Commission E, WG E/3

KEY WORDS: Matsu Belief, Matsu Temple, Bohai Rim, the Hall of Fujian in Yantai, style from QuanZhou, Heritage conservation

\begin{abstract}
:
Since the Yuan Dynasty, the belief of Matsu had started to spread from the birthplace to the northern coastal areas in China. Matsu worship developed to the pinnacle with the official promotion on account of the government's dependence on grain transported by sea since the mid-Qing Dynasty. A large amount of Matsu temples emerged in coastal cities of Bohai Rim where it still keeps a large number of them until now. It has much relationship between the spread of Matsu culture and the flow of Fujian population. It was one of the main building way that the Matsu temples attached to the local hall of Fujian in Bohai Rim. The Hall of Fujian in Yantai, Which was built with materials taken from Fujian, in the feature of traditional architectural style from QuanZhou, is very different from the local building style of Yantai. This case indicates that maritime culture of the south area had spread and developed in the north areas under the promotion of the population flow and the economic transaction. The essay introduces briefly about the development of Matsu culture in Bohai Rim and takes the case study of the Hall of Fujian in Yantai analyzing its causes and features, and the value as Matsu heritage. Then the paper will discuss the conservation of Matsu culture mere include the tangible and the intangible culture heritage around the origin area, the heritages of the spread area also have the same importance significance. With the evolution of the society, it calls urgent attention and protection of Matsu culture in Bohai Rim.
\end{abstract}

\section{INTRODUCTION}

In the fifth year of Xuanhe in the Northern Song Dynasty, the official advocacy and praise of Matsu began, which also meant that Matsu belief became the official belief from the witchcraft in the folk. In the Southern Song Dynasty, the expansion of overseas trade and the increasingly frequent maritime affairs accelerated the dissemination of Matsu belief. In the second year of Qingyuan (1196), the first Matsu temple was built in Quanzhou, marking that Matsu belief gradually walked out Puxian area to radiate to surrounding areas. The national unity was achieved in Yuan Dynasty, and as the capital of Yuan is located in Yan, which is far away from regions south of the Yangtze River, the prosper of the city and the numerous bodyguards all rely on the regions south of the Yangtze River. Based on the demand of delivering the tribute grain to the northern area, Matsu belief was disseminated quickly to Shandong and other northern regions along the grain transportation rout. Zheng He's seven voyages opened the approach to disseminate Matsu belief to overseas in the early of Qing Dynasty; by Qing Dynasty, with the increase in maritime activities, the development of folk commodity economy and the development needs of inland territory, Matsu belief was not only favored $b$ the government again and revived in the northern coastal regions, but also penetrated to the hinterland with the activity footprints of Fujian people.

If it is said that the generation, development and formalization of Matsu belief is a clue in the historical time, then the geospatial "surface" of the dissemination of belief culture developed along this "line". This "surface" roughly consists of the following areas: first, surrounding areas of the birthplace, including Fujian, Taiwan, Zhejiang, Guangdong and other southern coastal provinces, and a lot of scholars have studied the dissemination of the belief in these regions; second, the north district, mainly including Shandong, Liaoning, Hebei and
Beijing-Tianjin region in Bohai Rim, and since Yuan Dynasty, Matsu belief had been disseminated to this region through the grain transportation to form another Matsu belief cultural circle gradually in Bohai Rim; third, the west district, mainly referring to Jiangxi, Hunan, Hubei,Guizhou,Sichuan and other provinces westward from Fujian,and the large-scale migration in the South between the late Ming and early Qing Dynasties were the main socialdrivers(Figure1)

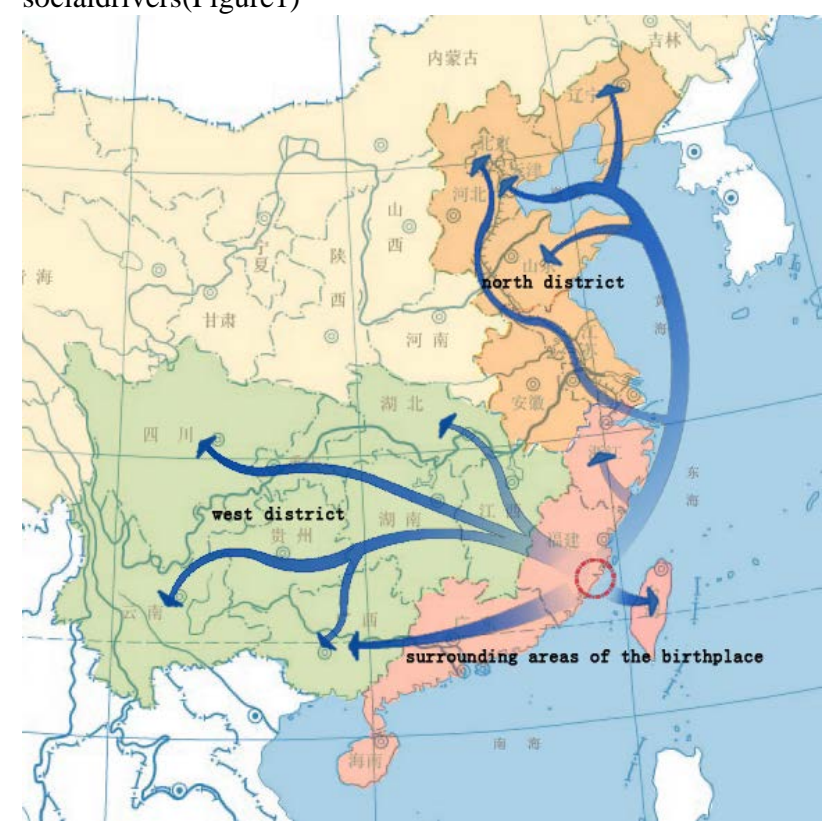

Figure 1. Dissemination of Matsu Belief

The spreading of Matsu belief reflects the socia-economic exchanges and the population migration in history, while Matsu temple is the physical-state record and crystalline of Matsu 
culture in the dissemination regions. As a sea goddess born in Fujian and spread in the southern coastal provinces, Matsu has strong regionalism, just like the language, people's life customs, architecture and so forth of Fujian. Therefore, the study on the construction and change of Matsu temples in the dissemination regions is not only the study of intangible culture, but also the study on architecture of the building skills in the cultural birthplaces and dissemination regions. In-depth studies have been made on the disseminations of Matsu belief so far, while studies about Matsu temples on architecture are very scarce.

The hall of Fujian in Yantai is a Matsu temple with larger scale in Bohai Rim, and is also a Matsu temple well preserved. As its main building was constructed with materials taken from Quanzhou, the hall of Fujian in Yantai is located in the old city with its style different from local traditional architectures, and its unique architectural culture and the inevitability of its social background deserves our analysis and study.

\section{DISSEMINATION OF MATSU BELIEF AND DISTRIBUTION OF MATSU TEMPLE IN BOHAI RIM}

\subsection{Dissemination of Matsu Belief and Distribution of Matsu Temple in Shandong Area}

The Bohai Rim consists of Laizhou Bay, Bohai Bay and Liaodong Bay, and contains Shandong, Hebei, Liaoning, Tianjin and other provinces and cities as well as nearly one hundred 1 ports along the coast. The coastline in Shandong is winding and zigzagging with the length of more than three thousand kilometers, and the safe harbors and ports for boats scattered all over like stars in the sky or men on a chessboard. Some ports had become important anchor ports for "Fujian and Zhejiang merchant ships” as early as Tang and Song Dynasty. Therefore, "the sacrifice for the Tianhou - there were numerous temples in the costal ports.”(Yuan Rongsou, 2011) According to the author's fieldwork and literature research, there were a lot of Matsu temples in Rizhao, Jiaozhou, Qingdao, Rongcheng, Yantai, Penglai and other places in Shandong Peninsula. As the river transport line also passes Shandong Province, there was another route to disseminate Matsu belief in Shandong, namely, dissemination along the canal, for example, the Matsu temples were also built in Dezhou, Jining, Donge and other counties in the history. 48 Matsu temples have been built in Shandong Province successively, among which, 37 temples were constructed along the coast(Yan Huachuan,2006), accounting for more than half, and now 5 temples survive and are located in coastal areas.

\subsection{Dissemination of Matsu Belief and Distribution of Matsu Temple in Else Area}

In early Ming Dynasty, Matsu belief entered LiaoniangProvince area from LvshunPort (Sun Xiaotian, 2011). The maritime prohibition was cancelled in the early Qing Dynasty, and grain carriers were allowed to bring more local products for transaction. The sea canal was further developed and extended to the whole Bohai Rim, and Matsu belief also developed and grew in Lvshun, Yingkou, Jinzhou, Dandong and other places along LiaodongBay with the merchant marine trade. There are four Matsu temples in LiaodongPeninsula currently. "First the Matsu temple, and then Tianjin garrison area.” This proverb is a figurative description of the significance of Matsu belief to the origin of Tianjin city. Since Yuan Dynasty, Tianjin had become water and land transportation hub converging vessels and vehicles and a portal for imperial capital and its surroundings. At that time, a Matsu temple was built on Dazhigu wharf and the three-branch river mouth. By Qing Dynasty, there had been nearly 20 Matsu temples in Tianjin. At present, the Tianjin Temple of the Queen of Heaven on the three-branch river still survives. Since Yuan Dynasty, and the grain ships coming from the south entered the Haihe River after docking in Dazhigu of Tianjin, and then sailed to Tongzhou through Baihe River, and at last arrived at Beijing via the Tonghui River, which can directly arrive at Datong Bridge in the east of the city. So Matsu temples were built along Tongzhou canal and under Datong Bridge in Beijing. The capital was moved to Beijing in early Ming Dynasty. The Ming government greatly strengthened the defense forces in the eastern hebei area around Tianjin and constructed and reinforced the Great Wall in Ji Town while setting the Tianjin garrison area. Due to the demand for shipment of a large number of army provisions, there had ever Matsu temples in Qinhuangdao of Hebei Province, the southern seaport of Shanhai Pass, and outside the west gate of Luanzhou and other places. (Figure 2)

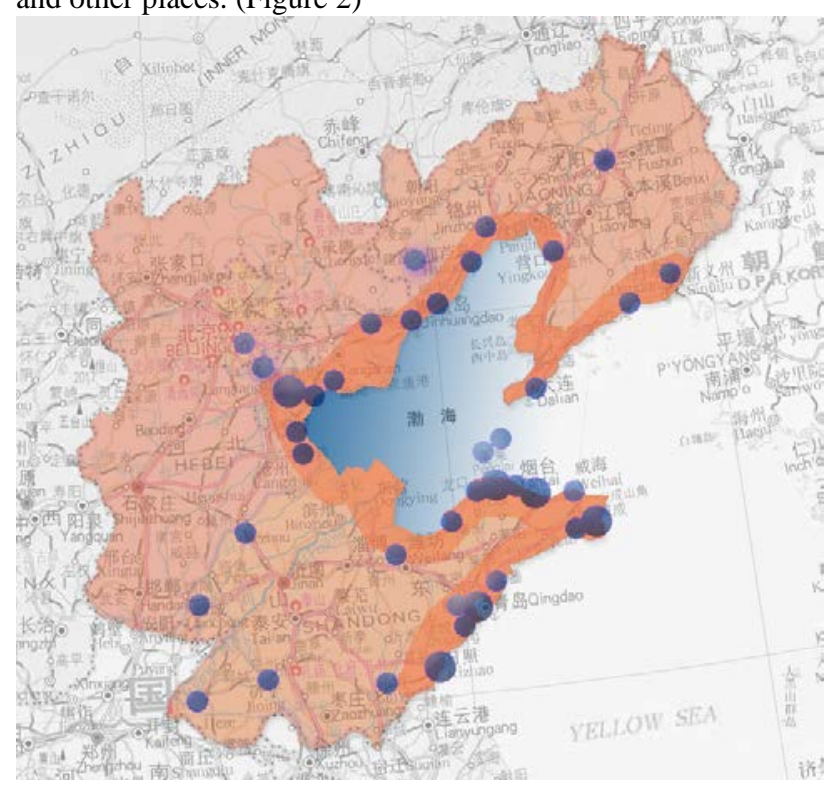

Figure 2. Distribution of Matsu Temple in Bohai Rim

\subsection{Inheritance of Matsu Belief in Bohai Rim}

The grain transporting system driven by the political power not only brought the resources of the South, but also promoted the North-South economic integration, and also promoted the cultural communication between north and south regions, pushing the formation of the Matsu belief cultural circle in Bohai Rim. But the foundation of belief culture lies in the believers. After imported to the Bohai Rim by the grain transporting system, the Matsu belief only relied on the official encomienda, officially built temples and official worship activities and lacked the foundation of believers and the sources of construction funds. The vitality of belief is limited. The existing ten Matsu temples prove that the Matsu belief culture in Bohai Rim did not disappear by the termination of grain transporting system. The worship of the Matsu in Penglai, Dagushan, and Dandong and other was integrated with other gods which guaranteed the number of believers, so that the belief can be continued; with the development of social economies, it was possible that the privates and the business communities funded to construct Matsu temples, and the Matsu temple in Yantai and Jinzhou were just funded by Fujian business groups. 


\section{BUILDING MOTIVATION AND ARCHITECTURAL FEATURES OF THE HALL OF FUJIAN IN YANTAI}

\subsection{Building Motivation}

After the mid-Qing Dynasty, with the development of commodity economy, frequent population movements and the flourishing of imperial examination system, the social organization of Business Group Hall emerged gradually. Proceeding from the desire to protect oneself and the deep love for the homeland, the halls became the base to open up their causes in the new place of residence, strengthening the geopolitical relations and occupational relations among people. The setting of gods in the hall was an important part to maintain the integrity of a hall, and the local God is the spiritual pillar on which people rely for existence. The Matsu gradually broke its original limitation of sea God during its dissemination and development to become the local God of Fujian. For example, the inscription on "Construction of Quanzhang Hall Stele" said: "We traveled to the places other than our own hometown, and our trading and voyage all rely on the blessing of the Queen of Heaven, so that we can often make benefits, our maritime trade is smooth and we are safe." (Shanghai Museum, 1980)Thus, the Business Group Hall became the new carrier to disseminate the Matsu belief in various ports, Beijing, even in the hinterland and Southeast Asian countries, the Matsu belief also migrated to various halls along with Fujian business groups and became the local god. The hall of Fujian in Yantai was just established in such a social trend.

After the second Opium War, according to the "Treaty of Tianjin”, Yantai (formerly known as Fushan County) was turned into a commercial port, becoming the first opening port in Shandong and rising from a fishing village in the garrison to an important trade center in the north in the first year in the region of Tongzhi (1862). Quanzhang business groups engaged in carrying trade were gathered here, and after over ten years of operation, they selected a location to build the hall near the grand temple of Yantai, and wanted to build a Taiwanese-style Temple of the Queen of Heaven in the south of the hall to flaunt their financial strength. Ye Tingming from Tongan (now Xiamen) of Fujian was responsible for this project. All building components were selected, constructed and decorated in Quanzhou and then were shipped to Yantan and assembled by Quanzhou craftsmen. It is required that each Fujian ship arriving at Yantai shall pay three hundred pence as the funds for building the hall. There were numerous building components, and the fleets of vessels for the transportation of building materials came and went in a continuous stream. Ships from Quanzhou to Yantai also carried building materials and components while carrying delicacies from south China. We can say that the whole Temple of the Queen of Heaven is "imported goods".

\subsection{Overall Layout}

The Hall of Fujian in Yantai is located in Yulan Street in the center of Yantai, facing south and the sea with $1 \mathrm{~km}$ away from the sea. It was built in the tenth year of Guangxu of Qing Dynasty (1884), and was completed in the $23^{\text {rd }}$ year of Guangxu of Qing Dynasty (1906). A series of buildings including the antechamber, guild hall, theater pavilion, front gate, great hall and so forth, and a few years later, the rear court room and the east and west gallery, forming the three-enclosed courtyard building group. The front gate and the great hall were completely built by Fujian craftsmen with Fujian building materials, and the building materials and components of the theater pavilion experienced shipwreck, so the existing theater pavilion were built by Fujian craftsmen with local materials in Yantai. In 1959, due to the road widening in the urban area, the rear court room and several east and west rooms were removed. Now it covers an area of over 3,500 square meters and construction area of over 1,500 square meters.

The layout of the hall(Figure 4) is stretched, and the buildings are spacious and gorgeous. On the central axis, the first building from north to south is the entrance hall, which is the meeting place of the hall. The entrance hall is three-rooms wide and five-purlins deep with one tall and two low hard peaks. The wooden structure is a straight girder-type tailiang frame and the wall was built by the ganged bricks with about 1 meter high Shile feet below. The penthouses on both sides of the hall can be access to the inner courtyard, and the theater pavilion is on the behind of the entrance hall. The theater pavilion is a square pavilion-style building.The front gate stands opposite the theater pavilion at a distance, and it is a building with the most cultural flavor of Fujian in this building group. The courtyard surrounded by the entrance hall, the great hall and east and west rooms is located behind the front gate. The great hall is located above the platform with double eaves and gable and hip roof, which is dignified and grand. The east and west rooms are covered by the flush gable roof, and are relatively low and simple.

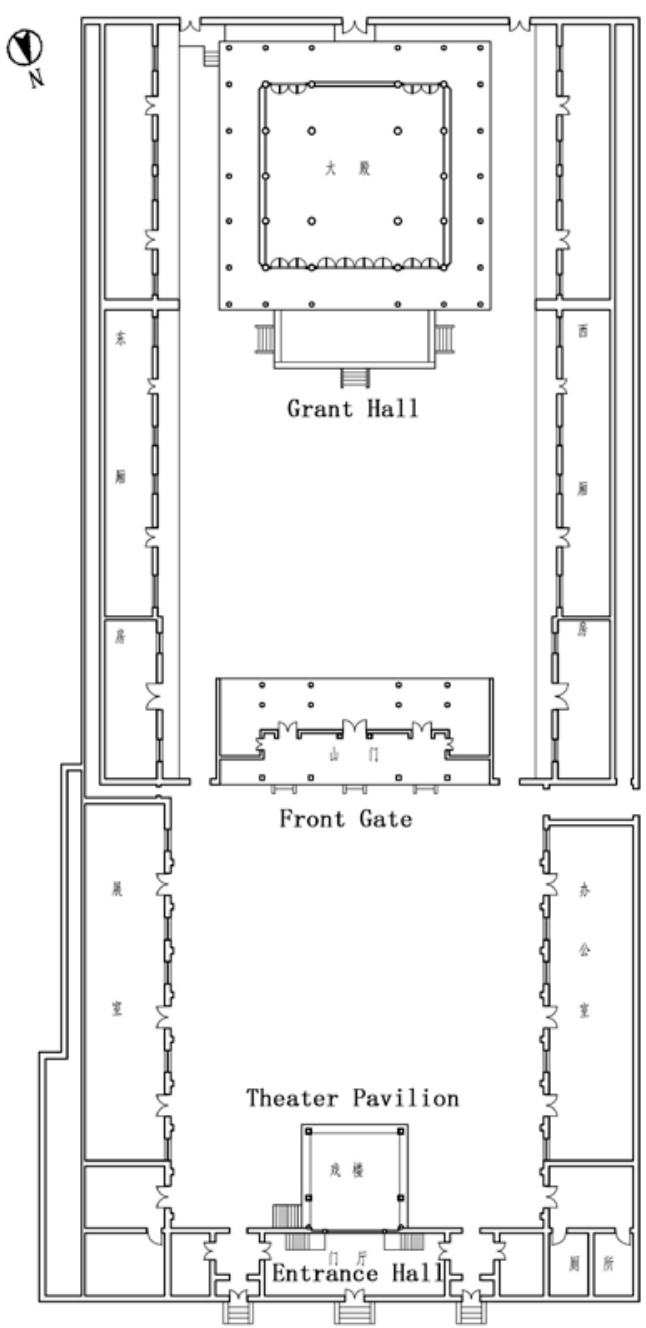

Figure 3. Overall Layout of the Hall of Fujian 


\subsection{Analysis on Architectural Features}

2.3.1 Front Gate: The front gate (Figure 4) is five-rooms wide and five-purlins beam deep with three pillars in the front and back. There are three rooms and four pillars in the middle, between them three doors were built with the drum piers in front of the doors. The doors are the plate ones with side doors on both sides. The stones are used as the main support structure for the lower part of the building, and the wood structures are used as the support and linkage on the upper part. The end of the bay is built with the masonry brick gable with the brick of $50 \times 120 \times 240$, the granite plinth on the lower part of the wall and the "four corner and six-inch" red ceramic floor tile. The wood structure is the typical tenon through frame. The camber piece is $8 \mathrm{~cm}$ thick, $23 \mathrm{~cm}$ high with lanky proportion near 1:3 (Yu Jianhua, 2002, which is relatively larger than the 4cm-thick camber piece of Quanzhou hall but with almost the same proportion. The space under the front and back eaves is open, and only the partition and door leaf are built on the middle pillar. Three rooms in the middle rise with the gable and hip roof, and two rooms on both sides are covered with the hard roof. The two ends of the roof rise very high, which may be because of the practice of "false house" and the rise in the wooden frame.

The wood and stone components of the front gate are gorgeous, and the sculpture is filled with Quanzhou features(Figure 5): the half bottom part of two columns in the middle place of the north side of the gate are the curled-up dragon pillars, which are made of diabase with the dragon claw carved on the column bases of wave pattern, downward dragon body, high dragon head and the powerful claws. It is the stone carving art treasure among front gate buildings. The columns and purlins playing the main structure role are decorated by red paint, other wood components are covered with carving or colored drawing with diverse themes.there are also lying men with wine pot in arms and breastfeeding women images on the end of tiebeams under the eave, which maintains the image feature of Arabs. This right reflects the international port identity of Quanzhou where the components were made(Figure 6).

As the hood of the roof is as deep as 2 meters, the roof appears to be very large compared with the lower frame, and the vertical lotus column was used on the outer eave, resulting in excessive weight; and the middle column is up to 7.7 meters high, while the diameter is only $30 \mathrm{~cm}$, so the slender proportion of the column is $1 / 26$. And the middle room is $6 \mathrm{~m}$ wide. In such as scale, there are only walls between the middle walls, lacking of connection between eave pillars, and due to the weak connection between each timber frame, so as to be failed to form a "frame". Compared with the memorial gateway of the palace of Tianhou in Quanzhou, the roof is so large that the thin tenon through structure is hard to support it, resulting in instable structure and distorted cornice in the front gate. After eight columns were added to support the eave during the repair of eave on both sides in 1982, the situation was improved. In contrast, the Hall of Fujian in Yantai has a much larger roof than the front gate of the palace of Tianhou in Quanzhou. The author guessed that the reason to increase the roof is to add the area of members available for carving and increase the architectural style. This should be related to the construction purpose of the investor - the business group, namely, the belief and the flaunting, while the timber frame is a strict system in line with the mechanical logics, and the tenon through frame has its own adaptability. Blindly increasing the proportion of the roof will inevitably bring about structural imbalances (Figure 7).

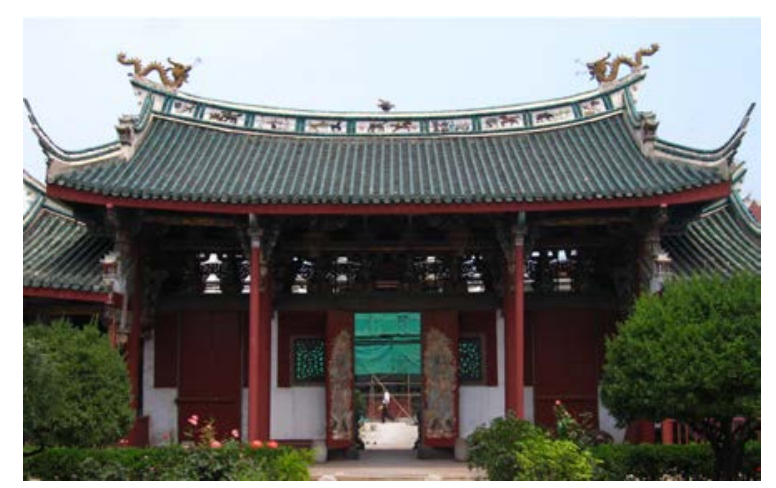

Figure 4 Elevation of the Front Gate

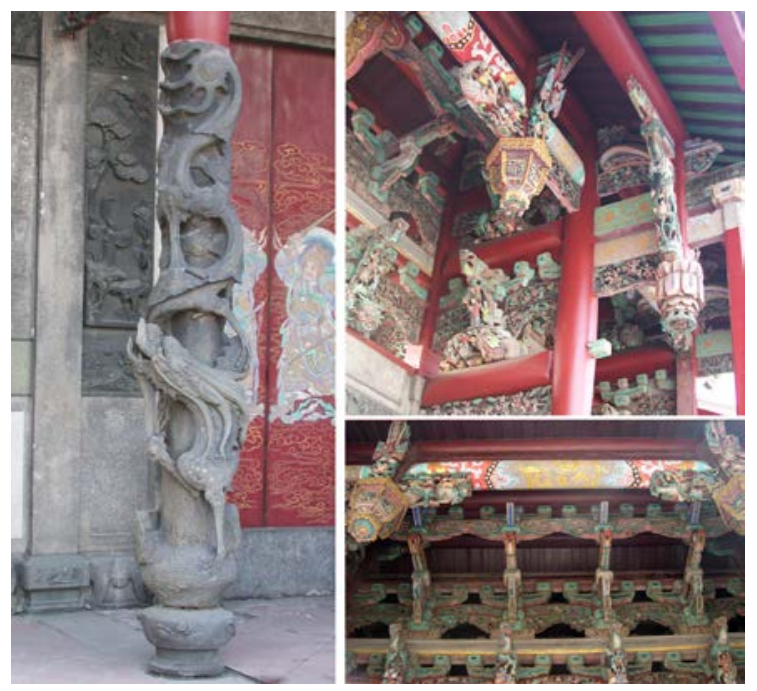

Figure 5 Sculptures on the Front Gate
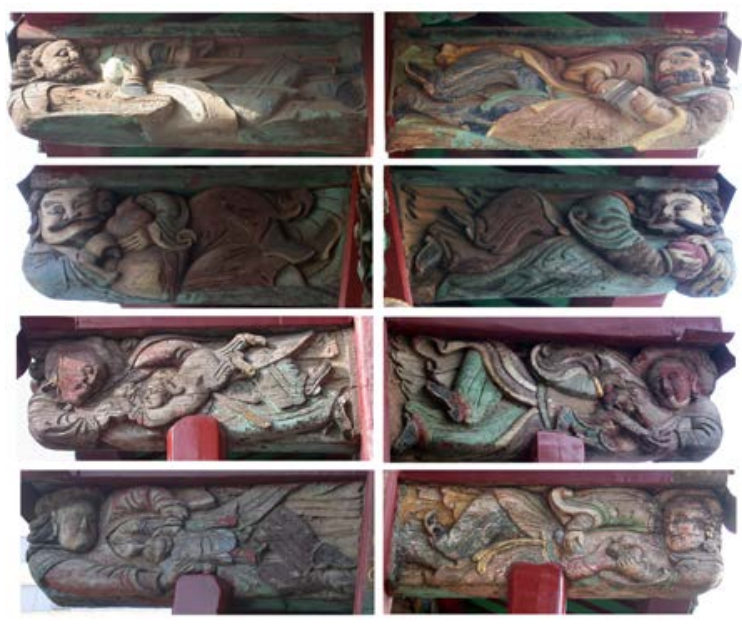

Figure 6 sculptures on the end of tiebeams of the Front Gate

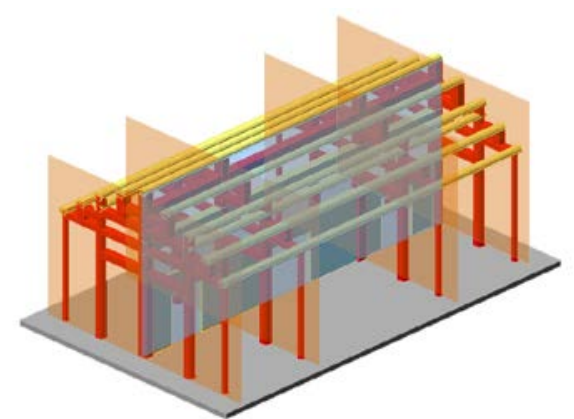

Figure 7 Overall Layout of the Hall of Fujian 
2.3.2 Great Hall: The great hall in the south of the front gate is situated on the $1 \mathrm{~m}$ high stylobate in front of which there is a platform and can be boarded on three sides. It is five-rooms wide and nineteen-purlins beam deep, and is surrounded by the ambulatories. It has double eaves, gable and hip roof and roof surface made of glazed title. The great hall shows a square structure, and although its wooden structure belongs to the tenon through frame like the front gate, its overall structure is more stable than that of the front gate due to the increase in the plain depth: there are totally forty columns in the great hall, which are distributed in three layers of column grip, including the inner, middle and outer one; the outermost circle is the verandah of the building, the second circle of columns connects straightly with the upper eave, and the establishment of door leaves and partitions between the columns in this circle strengthens the connection between the column and the upper part of the column; at the same time, the connection between the upper part of the column and the third circle of columns, namely, the four inner columns, is strengthened by the tiebeams. The four inner columns directly rise to under the roof to support the golden purlin. Due to the high height, the diameters of four inner columns are also increased. Meanwhile, the distribution of purline is intensive with only about $1 \mathrm{~m}$ horizontal spacing between purlins. Though the depth reaches nineteen-purlin beam, the connection between the roof truss from top to bottom is strengthened. Therefore, over more a century since its establishment, the great hall has not been the need for structural reinforcement or support.

The author found after the study on the Palace of Tianhou in Quanzhou (Figure 11)that the hall of Fujian in Yantai is similar with the Palace of Tianhou in Quanzhou in the height and roof slop of the great hall, which should be the most powerful proof for the association between the two. However, due to different construction era, the inner column grid and the beam bracket of the great hall in Yantai is greatly different from the Palace of Tianhou in Quanzhou. Compared with the reduced column pattern of the Palace of Tianhou in Quanzhou built in Song Dynasty, the inner column grid and structure of the great hall of the Hall in Yantai is more stable and reasonable.

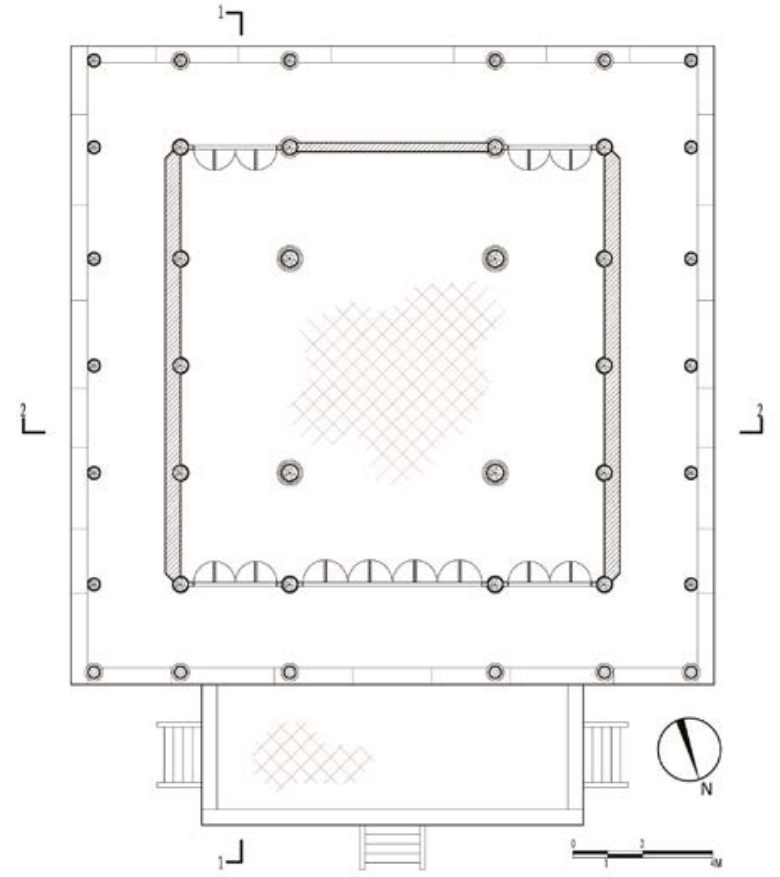

Figure 8. Plan of the Great Hall

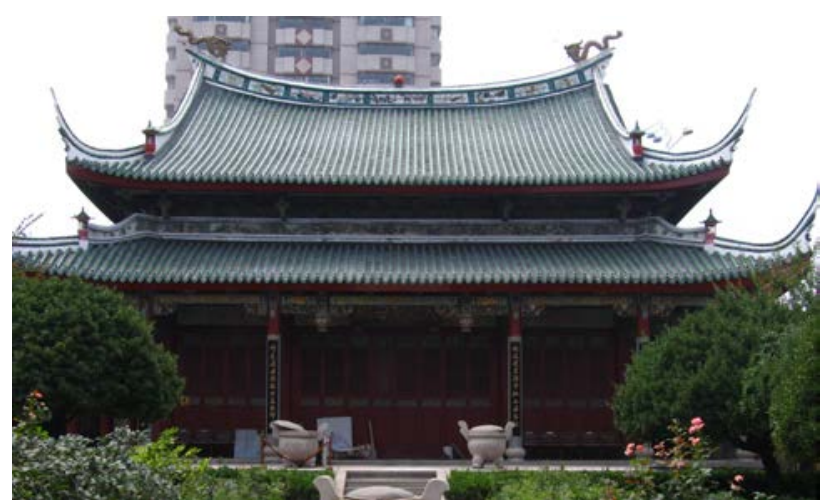

Figure 9. Elevation of the Great Hall

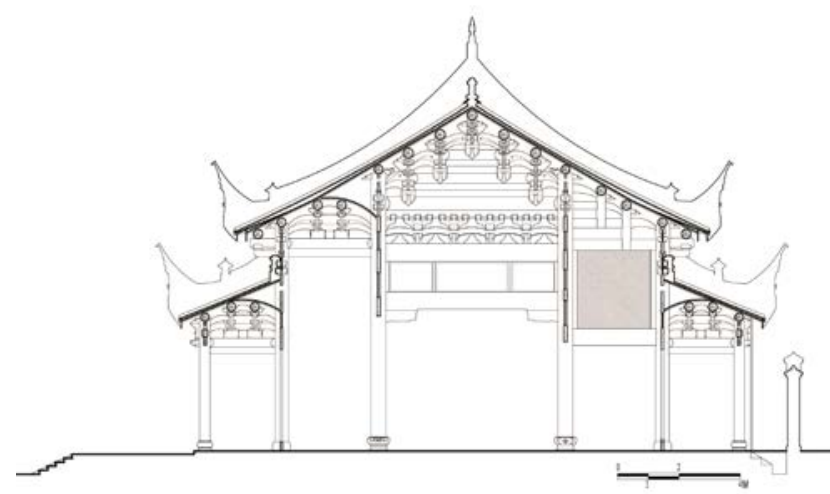

Figure 10. Section of the Great Hall

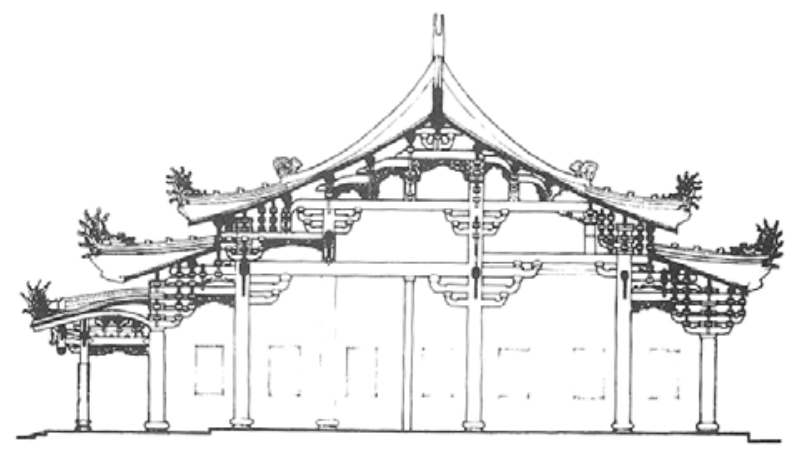

Figure 11. Section of the Palace of Tianhou in Quanzhou

2.3.3 Theater Pavilion: The theater pavilion( Figure 12) has four columns. The lower part of the column is the square stone column and the upper part is made an open mouth to embed the wooden columns to insert the beams and columns. The original components of the theater pavilion sunk in the sea cannot be known, and the current theater pavilion is different from the structure of of the front gate: its beams and columns are the straight ones with sections closer to square without curves. The structure of the gable side is very special: there are tiebeams between two columns in the depth direction, Short beams are set on the tiebeams between two columns and near the two columns, and the end of the beam outward supports the cornice, and the end inward is established another tiebeam. The ends of this tiebeam are connected with the cornices, and the short columns are set on it. As both ends of the short beams are subject to great downward pressure, its middle part is relatively weak, so two sole timbers with the same width to the beam are set under both ends of the short beam, which are integrated with the short beam after the oil decoration( Figure 13). 
During the survey in Quanzhou, the author found that the caisson is basically set inside the roof of the theater pavilion in Fujian region, beam frames are not exposed, and the similar roof was not found in Quanzhou.The survived theater pavilion in "Great Temple" near the Hall was built the $34^{\text {th }}$ year of Daoguang (1837) according to the record of the county annals. There are similarities between the theater pavilion structure of the great temple and that of the Hall, that is, solve the shelve problems on the mountain side with the shun beam. Their differences lie in that the theater pavilion of the great temple is the typical frame of rising beam ( Figure 14)while the theater pavilion of the Hall of Fujian is the typical frame of tenon. Due to a lack of building records, the author cannot confirm whether the traditional construction technology of Fujian exchanged with that in Yantai. But based on the theater pavilion, it is speculated that due to the wreck of the components of theater pavilion, Fujian craftsmen familiar with the tenon through frame may refer to the theater pavilion of the great temple in reproducing the theater pavilion or local craftsmen participated in the construction. The landing of imported building on the shore may be possible to exchange with local traditional architectural technology, resulting in the change. The roof truss of the theater pavilion is the example.

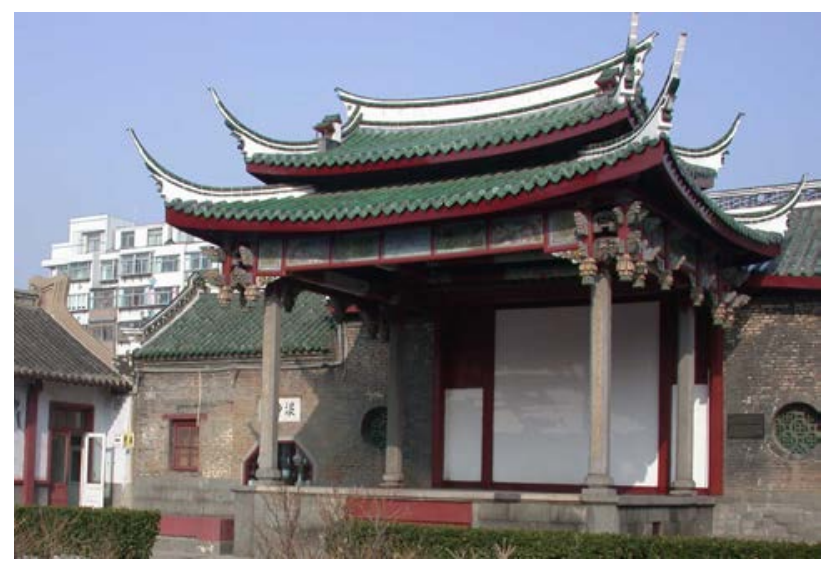

Figure 12. Elevation of the Theater Pavillion

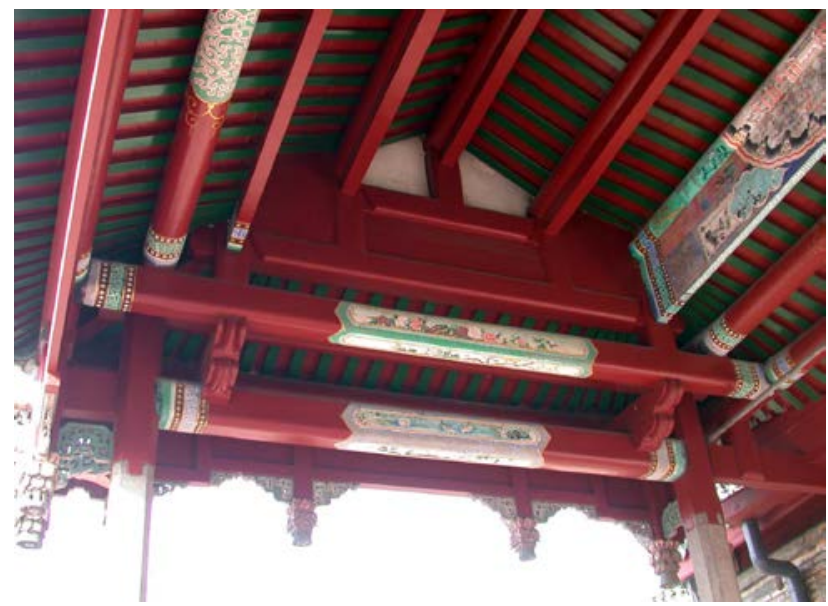

Figure 13. Frame of the Theater Pavillion

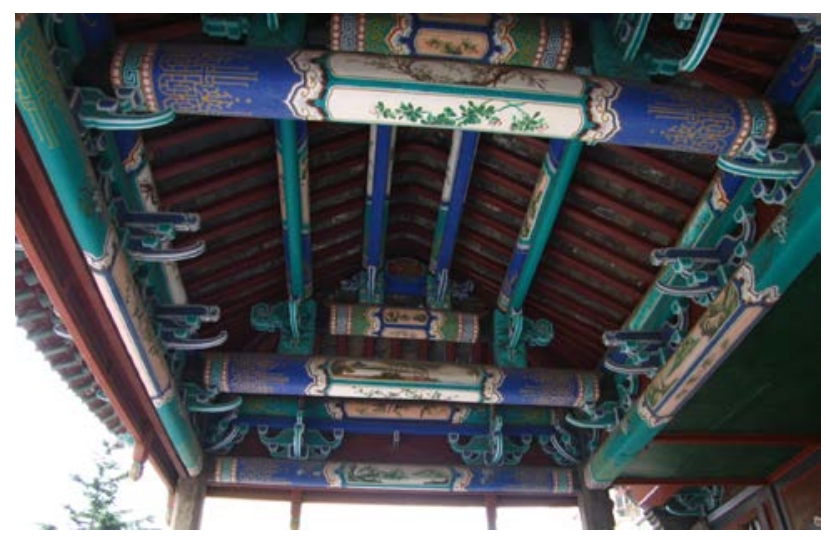

Figure 14. Frame of the Theater Pavillion in Great Temple

\section{DISCUSSION ON HERITAGE VALUE AND PROTECTIO F THE HALL N O OF FUJIAN IN YANTAI}

\subsection{Imported Building - a Unique Construction Culture}

The Hall of Fujian in Yantai built with the building materials and components of Fujian is not a unique case in the Bohai Rim, and the Hall in Jinzhou also partially used the building materials of Fujian. Port had been built in Jinzhou since Liao Dynasty, and became the transfer stop of the grain transporting in various dynasties as well as the distributing center for the interflow of commodities between the northeast, Hebei, inner Mongolia and Beijing-Tianjin region, which was described as "Jinzhou is the area gathering all businessmen". The existing Hall in Jinzhou was donated by Fujian merchants. Its flooring materials are the "four corner and six-inch" red bricks. Its wood and brick carvings are quite gorgeous, significantly better than other adjacent temples and have similar techniques and subjects to the carving in the Hall of Fujian in Yantai, which are suspected to be made by Fujian craftsmen. Until today, the construction mode related to the Matsu belief still continues, and Kunshan Huiju Temple completed in 2010 also took this construction mode. Such construction mode of shipping building materials from the birthplace of belief to the dissemination place becomes a unique architectural culture. According to the author's analysis, the reason for such architectural culture includes two aspects:

The first is the necessity to force the uniqueness. The local language, the folk belief and the architectural style of Fujian showed different characteristics to other regions. The buildings are the space to accommodate worship activities, and the container to carry the belief culture. Architectures are the most direct and most significant way of expression to manifest the geographical attribute of the belief. It becomes necessary to transport the building components from the birthplace of the belief to build temples at the expense of financial resources to prove the origin of belief. The second is that the universality brings feasibility. Due to the tenon-and-mortise work construction mode of traditional wooden architecture, the disassembly-assembly model became possible. The high-level development of the wooden structure technology in south Fujian also ensured the success of this model. In addition, compared with the land transport, the shipping transportation is characterized by the large capacity and high efficiency, and is able to adapt to the long-distance transport. The large-scale transportation in the ancient all used the waterway for travel, therefore, the shipping transportation is also a root cause for the appearance of buildings in south Fujian in a remote coastal city. 


\subsection{The historical witness of port city and one of the center} of Northern Matsu belief

The establishment of the Hall of Fujian in Yantai is the witness of business prosperity of Yantai County, and also recorded the development of the hall system in Yantai. In the early Ming Dynasty, the Matsu belief was passed to Yantai, and in the midQing Dynasty, the Matsu Temple was first built in Yantai County, later known as the "Great Temple". Due to the gathering of believers, its surrounding areas gradually became prosperous. During Tongzhi years, Fujian shipping groups transferred the hall from Penglai to near the Great Temple, and began to construct the hall buildings. After the "Great Temple" building group was nearly destroyed in 1974, the survival of Fujian Hall is more valuable, and has important historical value. At present, the Hall of Fujian in Yantai is still the most beautiful, splendid, and best preserved Matsu temple in the Bohai Rim. Because of its good geographical location and complete beautiful buildings, it becomes the center of Matsu belief cultural belief in the northern area together with the palace of Tianhou in Tianjin, Qingdao and other cities. In each birthday of the Matsu in the spring and the day Matsu going to the heaven in the autumn, the Yulan drama thanksgiving activities were held here. After centuries of continuity, today the Hall of Fujian still bears such function, and the "Yulan grand meeting" is held in the middle day of the lunar July each year to set altar to sacrifice the departed soul of the countrymen. It becomes the spiritual bond of Fujian people in Shandong Province, and has important social value.

\subsection{Discussion on the Heritage Protection of Matsu Culture in Bohai Rim}

During more than a century after its establishment, the Hall in Yantai suffered several changes: in 1959, due to the road widening in the urban area, the rear court room and several east and west rooms were removed. In 1982 and 1996, two maintenances were implemented, and several places were changed: the roof title was changed to glass round title and black pottery tile, and the wooden beams and columns of the great hall were painted with the color painting of Qing government, which is quite disproportionate to the architectural style of the south Fujian. The main ridge and surrounding ridges of the main hall and front gate were originally the sticky decorations, but were damaged with the passing of time, so they were replaced of the colored titles during the maintenance in 1982. The roof gable of the great hall is originally the wall with flush gable roof made of the red bricks, and was changed to the hanging one with the addition of wind deflector during the maintenance in 1982( Figure 15). It is thus clear that due to the inadequate protection, at the time the building was saved, its original style and crafts were also changed, bringing human injury. The damages occurred are irreversible, and although Fujian construction skills would be inevitably affected by local traditional technology after entering Yantai with the front gate as the example, reliable reference bases must be found for the future protection and maintenance project in the absence of historical construction data to carefully deduce the original state. In consideration of the association between the Hall in Yantai and Quanzhou in terms of construction, the detailed approach of the flowers, ridge decoration, colored painting and so forth of the Hall in Quanzhou can provide the reference to the original style for the future maintenance of the Hall of Fujian in Yantai; while the craftsmen are the guarantee of the continuation of original process, so the craftsmen from the south Fujian must be involved in the protection of the Hall in order to ensure the traditional architecture styles of the Hall of Fujian.
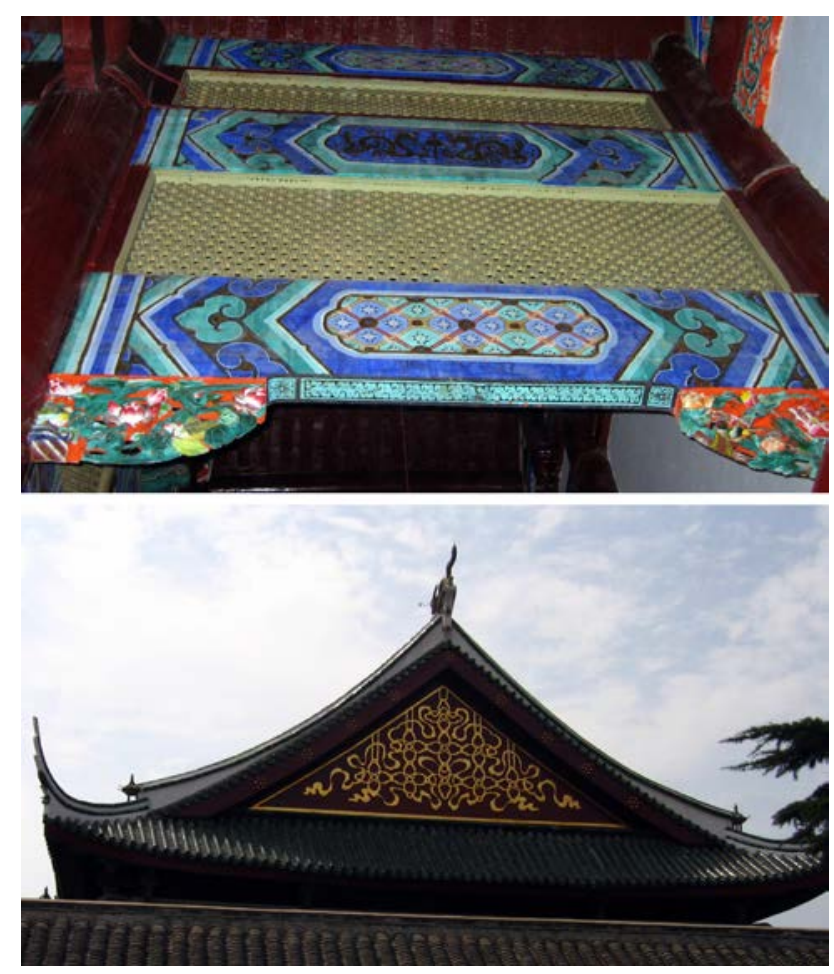

Figure 15. Damages of the conservation on the Great Hall

\section{CONCLUSIONS}

With the social development, the types of transportation increasingly diversify, and the transportation security has greatly improved. The Matsu belief culture shows a declining trend in the Bohai Rim. The reason is that for the majority of local residents, the Matsu does not be divorced from the range of sea God belief. In addition to maintaining and continuing worship activities related to the belief culture, how to protect and continue the intangible Matsu belief starting from protecting tangible cultural relics? First, the cities with the Matsu temples are important ports and counties in the history or the regions with developed business in the history, so the distribution situation of the Matsu temple in Bohai Rim is the record of the social and economic development history of the region. Secondly, due to the civil characteristic of the Matsu belief, a lot of relevant worship ceremony or construction situations were not recorded, resulting in the difficulty in studying the belief culture in this region now. Thus, the existing historical data or the historical data may be found in the future are valuable cultural heritage; moreover, the remaining Matsu temple buildings in this region now are all extremely precious entity heritage, and regardless of the styles, they record the history of the city, the dissemination of the belief and the construction of the building. Therefore, the architectural study on the Matsu temple is a loyal and detailed record of its construction history and skills, and the objective analysis on the architectural features and value of the Matsu temple to enrich the research content of the Matsu belief provides adequate and reliable basis for the protection of Matsu cultural heritage in this region.

\section{REFERENCES}

Shanghai Museum, 1980. Shanghai Epigraphy, Shanghai People's Publishing House, pp235-238 
Sun Xiaotian, 2011. Investigation of Matsu Culture in Liaoning Province - A Case Study of Donggang Gushanzhen, Minzu

University of China, pp43

Yuan Rongsou, 2011. the Local Annals of Jiao’ao, Qingdao Publishing House , pp 87

Yan Huachuan, 2006. The origin of Mazu belief and its propagation history research in Shandong, Shandong university, pp23

Yu Jianhua, 2002. the Hall of Fujian in Yantai and Its Survey, Traditional Chinese Architecture and Gardens, pp 57 